\title{
Efficacy and safety of the phytotherapeutic drug
} Canephron ${ }^{\circledR} \mathrm{N}$ in prevention and treatment of urogenital and gestational disease: review of clinical experience in Eastern Europe and Central Asia

This article was published in the following Dove Press journal:

Research and Reports in Urology

31 January 2013

Number of times this article has been viewed

\author{
Kurt G Naber \\ Technical University, Munich, Germany
}

Correspondence: Kurt G Naber

Karl-Bickleder Strasse 44c, 943I5

Straubing, Germany

Tel +49 942I 33369

Email kurt@nabers.de

\begin{abstract}
This review evaluates 17 clinical studies from 18 selected publications concerning the safety, tolerability, and additional effects of the phytotherapeutic drug, Canephron ${ }^{\circledR} \mathrm{N}$ (CAN, containing the medicinal plants, Centaurium erythraea, Levisticum officinale, and Rosmarinus officinalis) as standard therapy in various clinical settings. Its role in the prophylaxis and treatment of urinary tract infections in adults and in children, therapy and prophylaxis in adult patients with renal stones, treatment and prevention of urinary tract infections and other gestational diseases in pregnancy, and also its safety and tolerability. The dosage was as recommended and over a varying duration. Overall, CAN was shown to be effective in the treatment and prophylaxis of UTI compared with standard therapy, both in adults and children, and there was a reduced number of relapses. Children undergoing surgical correction of vesicoureteral reflux benefited from a prophylactic course of CAN. Ten-day add on therapy increased the rate of spontaneous elimination of kidney stones compared with standard therapy alone and may also have had a positive effect on stone prevention. Pregnant women showed earlier relief of symptoms and normalization of pyuria on additional treatment with the herbal combination. Only one adverse effect was reported (skin rash) in the 3115 patients included in this review. No teratogenic, embryotoxic, or fetotoxic effects, or negative interference with the psychological development or health of children born of mothers treated with the drug were reported. Because some of the studies were not well designed, their statistical significance remains unclear.
\end{abstract}

Keywords: Canephron ${ }^{\circledR} \mathrm{N}$, herbal remedy, urogenital disease, gestational disease

\section{Introduction}

Canephron $^{\circledR} \mathrm{N}$ (CAN, Bionorica SE, Neumarkt id Opf, Bayern, Germany) is a phytotherapeutic drug, the main ingredients of which are centaury (Centaurium erythraea), lovage (Levisticum officinale), and rosemary (Rosmarinus officinalis). The most active ingredients are phenolic glycosides and phenolcarboxylic acids (rosemary, lovage, and centaury), phthalides (centaury), secoiridoids (centaury), essential oils (lovage, rosemary), and flavonoids (centaury, rosemary).

One coated tablet contains Herba centaurii $18 \mathrm{mg}$, Radix levistici $18 \mathrm{mg}$, and Folia rosmarini $18 \mathrm{mg}$, and the $100 \mathrm{~g}$ drops contain $29 \mathrm{~g}$ alcoholic aqueous extract from Herba centaurii $0.6 \mathrm{~g}$, Radix levistici $0.6 \mathrm{~g}$, and Folia rosmarini $0.6 \mathrm{~g}$ (extract tincture, ethanol 59 vol\%). A number of pharmacological actions are attributed to the 
preparation, including diuretic, spasmolytic, anti-inflammatory, antioxidative, antibacterial, and nephroprotective effects.

In the Community of Independent States, CAN is registered for the following indications: chronic infections of the urinary bladder (cystitis) and kidneys (pyelonephritis); noninfectious chronic inflammation of the kidneys (glomerulonephritis, interstitial nephritis); and prophylaxis against and after removal of renal stones. It may be used during pregnancy and breastfeeding under medical supervision.

The recommended dosage is two coated tablets or 50 drops three times daily for adults, one coated tablet or 25 drops three times daily for school children, 15 drops three times daily for small children, and 10 drops three times daily for infants.

The clinical studies of the clinical indications, dosage regimens, and safety in the therapeutic use of CAN reviewed here were published in Belarus, Moldavia, Russia, Ukraine, and Uzbekistan.

\section{Materials and methods}

A total of 18 publications on urogenital infections from Belarus, Russia, and Ukraine were identified for review by Bionorica SE. There were seven publications from Russia, one from Belarus, eight from Ukraine, one from Moldavia, and one from Uzbekistan. ${ }^{1-18}$ Two publications described the same cohort of patients, leaving 17 clinical studies available for review, ${ }^{11,12}$ which involved mainly the following indications:

- Prevention and treatment of urinary tract infections (UTI) in adults (as additive therapy in four studies) $)^{1,2,9,10}$

- Prevention and treatment of UTI and urinary tract anomalies in children as additive therapy (in four studies which also investigated its use for vesicoureteral reflux and after surgical correction of vesicoureteral reflux and megaureter) ${ }^{6-8,16}$

- Prevention and treatment of renal stones in adults (as additive therapy in five studies) $)^{3,11,12,17,18}$

- Prevention and treatment of UTI and specific gestational diseases in pregnant women (as additive therapy in three studies of women with or without diabetes mellitus $)^{5,14,15}$

- Effects of CAN therapy on congenital malformation and postnatal development of children (two studies). ${ }^{4,13}$

\section{Results}

\section{Prevention and treatment of UTI in adults}

Of the four relevant studies, one by Sinyakova and Kosova was only observational and not controlled. ${ }^{1,2,9,10}$
The other three were comparative, including two which were prospective and randomized..$^{1,9,10}$ In the four studies, a total of 304 patients received the herbal compound either in addition to standard therapy during the acute phase or as prophylaxis (see Table 1 for dosage and duration). Although no patient experienced a relapse in the observational study during the first year, the results are difficult to interpret because there was no control group and the study groups were not well defined in terms of their previous UTI history. ${ }^{2}$

In the comparative study by Perepanova and Khazan, the groups of patients treated with and without the compound were too problematic to compare, and probably included historical controls. ${ }^{1}$ Nevertheless, the study showed a significant increase in diuresis, reduction of bacteriuria, and frequency and prolongation of recurrence-free periods compared with the control group.

A randomized prospective study by Dudar et al showed a significantly lower rate of relapse in patients with chronic recurrent pyelonephritis and cystitis who received the herbal remedy as prophylaxis for 3 months after standard therapy as compared with prophylaxis using an herbal tea. ${ }^{10}$ There was also a faster cure rate in patients receiving the herbal drug together with standard acute phase therapy compared with patients on standard therapy alone (statistical significance not reported).

Ivanov et al performed a similar study, but in type 2 diabetics with the metabolic syndrome. ${ }^{9}$ They demonstrated that recurrences of UTI in patients who received the herbal compound for prophylaxis over 3 months to prevent lower UTI and for 6 months to prevent upper UTI were in the same range as that achieved by conventional antimicrobial prophylaxis. Further, an antiproteinuric effect could be demonstrated in diabetic patients with low to moderately high microalbuminuria.

\section{Conclusion}

CAN had a prophylactic effect in reducing the frequency of relapses in chronic cystitis and showed a similar trend in upper UTI (pyelonephritis), including in type 2 diabetics with metabolic syndrome. An antiproteinuric effect was demonstrated in diabetic patients with low to moderately high microalbuminuria.

\section{Treatment and prophylaxis of UTI and other urinary pathology in children}

The remedy was administered to children in four studies, two for prevention of UTI/pyelonephritis and in the other two mainly for vesicoureteral reflux, either complicated by acute pyelonephritis or after surgical correction..$^{6-8,16}$ 
Table I Number of patients, duration of herbal therapy, and number of adverse events reported

\begin{tabular}{|c|c|c|c|c|c|}
\hline Reference & Patients (n) & Specified group & Duration & Adverse events & Dosage \\
\hline 6 & 43 & $\begin{array}{l}\text { Children aged } 4 \text { months } \\
\text { to } 15 \text { years }\end{array}$ & 3 months & One skin rash & $\begin{array}{l}7-15 \text { years, } 25 \text { drops tid; } \\
\text { I-7 years, I5 drops tid; } \\
\text { infants, } 10 \text { drops tid }\end{array}$ \\
\hline 7 & 22 & $\begin{array}{l}\text { Children ( } 14 \text { females, } 8 \text { males, } \\
\text { aged } 8.8 \pm 0.6 \text { months) }\end{array}$ & One month & No report & $\begin{array}{l}\text { Preschool children, } \\
\text { I } 5 \text { drops tid; children } \\
>7 \text { years, one tablet tid }\end{array}$ \\
\hline 8 & 30 & Children (28 females, 2 males) & Not specified & 0 & Not given \\
\hline 16 & 226 & Children & $\begin{array}{l}\text { Maximum } \\
3 \text { months }\end{array}$ & No specific report & $\begin{array}{l}10-25 \text { drops tid } \\
\text { according to age }\end{array}$ \\
\hline I & 27 & Adults ( 25 females, 2 males) & 3 months & 0 & 2 tablets or 50 drops tid \\
\hline 2 & 60 & Adults ( 21 females, 26 males) & I month & 0 & 2 tablets or 50 drops tid \\
\hline 3 & 47 & Adults (females) & I month & 0 & 2 tablets tid \\
\hline 9 & 65 & Adults & 3 months & 0 & 2 tablets or 50 drops tid \\
\hline 9 & 62 & Adults & 6 months & 0 & 2 tablets or 50 drops tid \\
\hline 10 & 60 & Adults & 3 months & No report & 2 tablets or 50 drops tid \\
\hline $11+12$ & 110 & Adults & 2 months & No specific report & $\begin{array}{l}2 \text { tablets tid for } 4 \text { weeks } \\
\text { OR } 2 \text { tablets or } 50 \text { drops } \\
\text { tid for } 8 \text { weeks }\end{array}$ \\
\hline 17 & 135 & Adults & I month & 0 & 2 tablets tid \\
\hline 18 & 32 & Adults & 2 months & 0 & 50 drops tid \\
\hline 18 & 18 & Adults & 4 months & 0 & 50 drops tid \\
\hline 5 & 300 & Pregnant women & $\begin{array}{l}3 \text { weeks, } \\
\text { I-2 weeks/month }\end{array}$ & No specific report & 2 tablets tid \\
\hline 14 & 30 & Pregnant women & I month & No specific report & 50 drops tid \\
\hline 15 & 50 & Pregnant women & $14-50$ days & No specific report & 2 tablets or 50 drops tid \\
\hline 4 & 115 & Pregnant women & $\mathrm{I}-2$ months & 0 & 2 tablets or 50 drops tid \\
\hline 13 & 1647 & Pregnant women & 3-28 weeks & 0 & 2 tablets or 50 drops tid \\
\hline
\end{tabular}

Notes: No report, safety and tolerability are not mentioned; no specific report, good safety and tolerance is only mentioned in general without specific analysis of the current study.

Abbreviation: tid, three times daily.

In one prospectively randomized (2:1), comparative clinical study by Sukalo et al, children with lower UTI and acute or chronic pyelonephritis were treated with antibiotics alone $(n=15)$ or antibiotics combined with the herbal product at the dosage recommended for their age (exact dosage and duration of therapy not stated). ${ }^{8}$ The combination therapy resulted in earlier normalization of urine (parameters not specified). No long-term follow-up for recurrence was mentioned. The therapy was considered to be safe and well tolerated.

In the comparative study by Voznesenskaya and Kutafina, ${ }^{6}$ 129 children with acute pyelonephritis were divided into three groups after termination of antibiotic therapy as follows: group $1(n=43)$ received the herbal medicine (exact dosage stated to be that recommended for their age); group $2(n=51)$ received nitrofurantoin $1.5-2 \mathrm{mg} / \mathrm{kg}$ for 3 months; and group $3(n=35)$ served as controls and received no prophylaxis following antibiotic therapy. The study demonstrated a significant reduction of recurrences in the groups receiving prophylaxis as compared with the controls, but with fewer adverse events in the group receiving the herbal treatment than in that receiving nitrofurantoin.
In one of the two remaining studies, the three-herb combination was administered for up to 3 months to 226 children either with vesicoureteral reflux complicated by acute pyelonephritis or after surgical correction of vesicoureteral reflux or megaureter. ${ }^{16}$ However, this was only an observational study. According to the author, all improvements seen after 3 months of herbal therapy were similar to the ones obtained after one year without herbal treatment. These findings should be validated in a well designed, prospective, randomized study. Good safety and tolerability in children is only mentioned in general, and no analysis for the specific study population is reported.

The comparative study by Kirillov et $\mathrm{al}^{7}$ included 44 children undergoing surgical correction of grade III-IV vesicoureteral reflux who were divided into two groups, one of which received the phytocombination (see Table 1 for dosage) one week prior to surgery and 3 weeks after surgery, and were followed up for 2 months after surgery. A positive effect was seen in children with vesicoureteral reflux and after surgical correction of vesicoureteral reflux and megaureter in the early postoperative phase for up to 3 weeks. No results 
are given on longer-term follow-up. There were no comments on safety and tolerability of the study treatment.

\section{Conclusion}

The effects of addition of the herbal remedy to antibiotic therapy for prevention of acute pyelonephritis in children were comparable with those achieved by prophylaxis using nitrofurantoin alone for 3 months. Both regimens significantly reduced the rate of relapse after antibiotic therapy for acute pyelonephritis as compared with no prophylaxis. However, the herbal drug was better tolerated than nitrofurantoin. There was a positive effect in children undergoing surgical correction of vesicoureteral reflux with regard to postoperative pyelonephritis and restoration of kidney function in the early postoperative phase up to 3 weeks, when the phytocombination was administered one week before and for 2 weeks after surgery. Some parameters were significantly improved as compared with the control group, ie, increased diuresis, earlier restoration of bladder function (not well defined), higher renal arterial blood flow, and reduced vascular resistance as measured by Doppler sonography.

\section{Prevention and treatment of renal stone disease in adults}

Patients with urolithiasis received the herbal combination as addon therapy in five studies. ${ }^{3,11,12,17,18}$ In an observational, uncontrolled study by Shaplygin and Monakov, ${ }^{3}$ a reduction of bacteriuria and leukocyturia was noted in 47 patients treated for 4 weeks and followed up for 6 months.

In the two publications by Chernenko et al, a total of 110 patients with urolithiasis were treated for 8 weeks, and 24 patients served as controls. ${ }^{11,12}$ In both publications, the same cohort of patients was involved, although the grouping of patients was slightly different. Whether the control group was historical or randomized is not clear, so the statistical evaluation has to be interpreted with caution. Nevertheless, the authors observed a significant $(P<0.05)$ increase in 24-hour diuresis, increased urinary $\mathrm{pH}$, and decreased urinary uric acid levels. All these parameters can be considered beneficial for metaprophylaxis of urate and calcium oxalate stone disease. The recurrence rate in the study group was also lower than in the control group. Treatment with the herbal drug was considered safe and well tolerated in all 157 cases.

In a randomized, open-label, single-center addon cohort study published by Ceban, 237 patients with renoureteral stones up to $0.7 \mathrm{~cm}$ in diameter and without disruption of the urinary tract or acute obstructive pyelonephritis were treated using standard therapy (anti-inflammatory, analgesic, or spasmolytic therapy) with $(n=137)$ and without $(n=102)$ the herbal remedy (see Table 1 for dosage). ${ }^{17}$ During the first 10 days, when the patients were hospitalized, the combination group showed higher rates of spontaneous elimination of renal stones (72.7\% versus 33.3\%), upper ureteric stones $(71.4 \%$ versus $37.5 \%)$, middle ureteric stones $(66.6 \%$ versus $40 \%$ ), and lower ureteric stones ( $90 \%$ versus $55.5 \%$ ). After 10 days of treatment, initial leukocyturia was reduced from $64.4 \%$ to $6.9 \%$ in the study group, but increased from $44.1 \%$ to $53.4 \%$ in the control group. The stones which did not disappear with medical therapy were treated using extracorporeal shock wave lithotripsy, ureteroscopy with stone extraction, or ureteric stent insertion, as appropriate. One month after cessation of treatment, there was a marked increase in mean daily urine volume in the study group as compared with the control group. Mean urinary $\mathrm{pH}$ increased from 5.6 to 6.4 in the study group and remained almost stable in the control group (5.7-5.8). Addon treatment with the phytocombination was considered to be safe and well tolerated in all cases.

In the observational study by Gaybullaev and Kariev, 32 (2008-2009) and 18 (2010-2011) patients with idiopathic, uncomplicated calcium oxalate renal stones were treated during autumn and winter with the herbal drug (see Table 1 for dosage). ${ }^{18}$ Diuresis and fluid intake were measured from patient diaries. In addition, urine $\mathrm{pH}$ and urinary excretion rates of oxalate, calcium, magnesium, and citric acid were measured, and from these data, the ionic activity index $\left(\mathrm{AP}_{\mathrm{CaOx}}\right.$ index, a risk factor for stone formation) and crystalluria rates were calculated. ${ }^{19-21}$ The study documented a slight increase of diuresis. Urinary excretion of oxalate (significantly), calcium (trend), and citric acid (trend) decreased, but excretion of magnesium increased (significantly) during therapy. The authors reported a significant decrease in ionic activity index and crystalluria rate, and interpreted the results as a trend towards decreased lithogenesis, recommending a prolonged course of treatment with the herbal combination in patients with uncomplicated idiopathic calcium urolithiasis. The treatment was considered safe, and no adverse reactions were reported.

\section{Conclusion}

Additional treatment with this herbal remedy may have a positive effect in patients with urolithiasis and after stone removal. In one randomized, open-label, single-center addon cohort study, it was demonstrated that the rate of spontaneous 
elimination of renoureteral calcium stones up to $0.7 \mathrm{~cm}$ diameter within the first 10 days of therapy was higher in the study group receiving the herbal product than in the control group. A prolonged course of treatment in patients with uncomplicated idiopathic calcium urolithiasis could reduce the risk of recurrence of stone disease, as shown by a decrease in the ionic activity index and rate of crystalluria.

\section{Prevention and treatment of UTI and related diseases in pregnancy}

In three studies, the additional effects of the herbal remedy were investigated in pregnant women, including the puerperium. ${ }^{5,14,15}$ The study by Ordzhonikidze et al included 300 pregnant women suffering from asymptomatic bacteriuria, gestational pyelonephritis, or exacerbation of chronic pyelonephritis (group 1) or from chronic urinary tract disease without current exacerbation (group 2). ${ }^{5}$

Patients were treated in addition to standard therapy with the herbal drug (for dosage, see Table 1) for 3 weeks, and thereafter for one week every month until delivery or, in the event of urinary tract anomalies or hydronephrosis, for 2 weeks every month. All the women also received the phytomedicine during the last week of pregnancy and for 7-10 days after delivery according to the same regimen as stated above.

As expected, group 2 performed better than group 1 . From their historical experience, the authors described a beneficial effect of the herbal compound during pregnancy and puerperium, which needs to be confirmed in a well designed controlled clinical study.

Medved et al investigated the effect of the herbal drug (see Table 1 for dosage) when used in addition to standard therapy in 30 pregnant women with type 1 diabetes mellitus and gestational pyelonephritis $(n=18)$ or aggravation (exacerbation) of chronic pyelonephritis $(n=12)$, and compared the results with a historical group of 60 patients with similar underlying conditions. ${ }^{14}$ In this observational clinical study, the authors reported significantly $(P<0.05)$ faster normalization of pyuria and a significant $(P<0.01)$ reduction in recurrences of pyelonephritis in women with gestational or chronic pyelonephritis as compared with the historical controls. Again, these findings should be confirmed in a well designed prospective, randomized, double-blind study.

The third study by Potapov et al was a prospective, randomized, controlled clinical study including 85 pregnant women with a range of renal pathologies. ${ }^{15}$ It is not clear why numbers in the two groups are so different or if randomization took place. Additional therapy with the herbal drug (see Table 1 for dosage) resulted in significantly $(P<0.05)$ earlier relief of symptoms (pain, dysuria, nocturia), a significantly higher normalization rate of pyuria after 7 days of therapy, a higher rate of microbial eradication, and a greater reduction of body weight than in the control group. The significance of the two latter findings is not discussed. In all three studies, no specific evaluation of safety and tolerability of the additional herbal therapy was performed, and its good safety and tolerability was only mentioned in general.

\section{Conclusion}

Additional herbal therapy at the stated dosage for varying lengths of time (eg, 4-8 weeks or until delivery) may have a positive effect on pregnant women with different renal pathologies with and without diabetes mellitus.

\section{Safety and tolerability}

In the 17 studies reviewed, 3079 patients were treated with the herbal compound using a variety of regimens (one week to 6 months, see Table 1). A total of 321 children (aged 4 months to 15 years) received the three-herb combination over a course of 1-3 months. The only adverse event reported was one episode of skin rash in a child with a history of severe allergic reactions. A total of 616 adults (pregnant women excluded, mainly women, but gender not always specified) received the herbal compound over 1-6 months. For 446 patients, the safety and tolerability of the herbal therapy are explicitly mentioned in the studies, and no adverse events were reported. In total, 2142 pregnant women received the herbal medicine over a course of 2-28 weeks. Safety and tolerability of the herbal therapy is explicitly mentioned for 1762 patients, and no adverse events were reported.

The potential for effects of the herbal treatment on congenital malformation rates and postnatal development of children was investigated in two studies. ${ }^{4,13}$ A study by Repina et al investigated 115 children ( 65 girls and 52 boys) aged 5 months to 3.5 years and born to women who received the treatment during pregnancy (except during the first 16 weeks, see Table 1). ${ }^{4}$ No adverse effects on the fetus were observed during pregnancy or on the psychophysical development and health of children born to mothers treated with the herbal remedy.

Medved and Islamova investigated the possibility of teratogenic, embryotoxic, and fetotoxic effects from the three-herb mixture during pregnancy in 1647 women. ${ }^{13}$ In 1220 cases, the analysis was retrospective (from medical 
records) and in 427 cases was prospective. There were 1647 newborns from January 2003 to December 2007. There was no evidence of any teratogenic, embryotoxic, or fetotoxic effect from administration of the product.

\section{Conclusion}

In the studies reviewed, treatment with the herbal product was considered to be safe and well tolerated by pregnant women, with no teratogenic, embryotoxic, or fetotoxic effects or any negative interference with the psychophysical development and health of children born to treated mothers. Given that there are some study limitations (eg, only pregnancies ending with a delivery were reported, thus excluding interruptions and abortions, and lack of untreated control subjects), as with most drugs, this herbal remedy should be used with caution and only under medical supervision during pregnancy, especially during the first trimester.

\section{Discussion}

This review includes 17 published investigator-initiated studies from the Community of Independent States on the use of this herbal remedy in the indications for which it is registered in these countries. The quality of the studies was heterogeneous. Some were only observational studies and some included historical controls. The prospective, randomized studies usually did not mention if the patient and/or the investigator were blinded in regard to the therapeutic arm. Differences between comparative groups were not well evaluated statistically in these studies. Therefore, it remains unclear whether the differences observed are statistically significant or not. However, the herbal compound was used for a broad spectrum of indications, including treatment and prophylaxis of UTI as well as other pathologies of the urinary tract.

The prevention and treatment of UTI and other urinary pathologies was evaluated in three comparative and one observational study, ${ }^{6-8,16}$ including a total of 321 children. In two of the studies, a significant reduction in recurrence of pyelonephritis or lower UTI was shown. ${ }^{6,8}$ One study compared patients with acute pyelonephritis after 3 months of prophylaxis using the herbal compound with or without standard antimicrobial prophylaxis, ${ }^{6}$ and reported fewer adverse events with herbal prophylaxis than with antimicrobial prophylaxis. In another two studies, children underwent surgical correction of vesicoureteral reflux or megaureter. ${ }^{7,16}$ The impact of the herbal treatment administered one week before and 2 weeks after surgery was investigated on the occurrence of postoperative pyelonephritis and restoration of kidney function was investigated for up to 3 weeks in the early postoperative period. One study was only observational and included historical controls. ${ }^{16}$ Surrogate parameters (diuresis, restoration of bladder function, renal arterial blood flow, vascular resistance) were significantly improved compared with the control group. However, a reduction in postoperative pyelonephritic exacerbations was not found, because there were few such events in either groups. Nevertheless, there seems to be a positive effect on restoration of kidney function to be gained from perioperative administration of the herbal drug, which needs to be further confirmed in a well designed study including better matched controls. However, it has to be taken into account that there are many logistic and ethical problems in performing well designed, prospective, randomized, double-blind, placebo-controlled trials in children. The reported tolerability in children was very good, with only one allergic skin reaction reported.

Prevention and treatment of UTI in adults was evaluated in four studies including 274 nonpregnant adults. . $2,9,10^{2}$ Unfortunately, the exact number of males and females was not always stated. These studies investigated the impact of the phytomedicine on the prevention of recurrent UTI episodes. Two studies in recurrent UTI were either observational or controlled by a historical cohort, and the other two studies were prospective, randomized, open-label comparative studies. ${ }^{1,2,9,10}$ The latter two studies showed a significant reduction in the number of pyelonephritic exacerbations and recurrences of cystitis. The problem with these two studies is that males and females as well as pyelonephritic and cystitic recurrences were reported together. When the total number of patients was stratified according to gender and upper and lower UTI, the numbers became too low for the studies to be adequately statistically powered. However, given that there are not many suitable antibiotics available for the prevention of recurrent UTI and because the European Association of Urology guidelines on urogenital infections ${ }^{22}$ recommend that antimicrobial prophylaxis should only be considered after counseling, possible behavioral modifications, and nonantimicrobial measures have been attempted, investigation of nonantimicrobial management for recurrent UTI should be of high priority.

Therefore, to establish the definitive role of CAN as prophylaxis for recurrent UTI, well designed, prospective, randomized, placebo-controlled studies are needed. This should be possible to do at least in otherwise healthy women with recurrent uncomplicated cystitis because of the high number of patients suffering from this condition. Clinical studies in recurrent pyelonephritic exacerbations or recurrent 
lower and upper tract UTI in men are more difficult to perform due to the smaller number of men suffering from these conditions.

The role of the three-plant compound for treatment and metaphylaxis of nephrolithiasis was analyzed in five studies including a total of 342 adult patients..$^{3,11,12,17,18}$ One laboratory study included patients with calcium oxalate nephrolithiasis, and investigated possible risk factors for stone recurrence using the lithogenic index, which represents a complex product of renal excretion of various prolithogenic and antilithogenic minerals, such as calcium, oxalate, and magnesium. ${ }^{18}$ This study showed a significant reduction in the lithogenic index after administration of the herbal product for about 3 weeks, providing a good theoretical basis to suggest at least that this agent may also play a positive role in the metaphylaxis of urolithiasis. The change in urinary $\mathrm{pH}$ was slightly towards the alkaline range, which might further be favorable for prevention of urate and calcium oxalate stone formation. The effect of increased diuresis is probably not so important, because long-term diuresis depends mainly on fluid intake, physical activity, and environmental factors. Therefore, the patient is usually advised to adapt fluid intake to the desirable amount of urine to be excreted. This steering method works ultimately much better than standardized recommendations for daily fluid intake. The control groups used in the studies which showed a reduction in stone recurrence by treatment with the herbal medicine were not clearly defined, and were probably historical. ${ }^{11,12}$

In one observational study of patients with urolithiasis, a reduction in bacteriuria and pyuria could be demonstrated, but the clinical significance of this remains unclear because the study was not well controlled. ${ }^{3}$ However, the clinical study including 135 patients with calcium oxalate urolithiasis demonstrated a significant positive effect on spontaneous elimination of small urinary calcium stones (up to $0.7 \mathrm{~cm}$ in diameter) at all sites (kidney, upper, middle, and lower ureter). ${ }^{17}$ Clearly, conservative therapy with CAN is only suitable if there is no acute infection or any kind of obstruction present. Unfortunately, in modern medicine, very often instrumental stone elimination is performed early after the first episode of renal colic, because neither the patient nor the physician would like to take the risk for further ureteral colic episodes, which of course could be prevented by appropriate medication. However, the more conservative approach may well reduce the inherent risk of need for instrumentation, and ultimately the majority of patients may benefit from this more conservative approach.
In the five studies including 2142 pregnant and puerperal women, the herbal preparation was administered for various reasons, including asymptomatic bacteriuria, gestational pyelonephritis, or a history of chronic urinary tract disease. ${ }^{4,5,13-15}$ Most of the studies are observational because of the known problem of performing prospective, randomized, placebo-controlled studies during pregnancy. Randomization was obviously performed in one study, but it is difficult to explain why the numbers in each group were so different. ${ }^{15}$ Nevertheless, in pregnant women with different renal pathologies, there seems to be a positive effect from the herbal medicine with regard to earlier relief of symptoms (pain, dysuria, nocturia), a significantly higher rate of normalization of pyuria after 7 days of therapy, a higher rate of microbiological eradication, and a greater decrease in body weight than in the control group.

When using any drug during pregnancy, safety and tolerability is always an important issue. No adverse events were reported in the 1762 pregnant women treated with the compound. Moreover, in two studies, any possible effect of CAN on congenital malformation and postnatal development of children was investigated. ${ }^{4,14}$ There were no unwanted effects on the fetus or on the psychophysical development and health of the children born to women who took the study drug. Although there was no evidence of any teratogenic, embryotoxic, or fetotoxic effects from administration of the phytodrug, this study has some limitations, in that there was no information given regarding possible cases of miscarriage and no matched control group was included.

\section{Conclusion}

It can be concluded that, due to its diuretic, spasmolytic, anti-inflammatory, antioxidative, antibacterial, and nephroprotective properties, CAN seems to have a positive clinical impact on infectious and inflammatory processes within the urinary tract and on spontaneous elimination of small calcium oxalate stones. It may also be indicated for stone metaphylaxis because of its ability to reduce the risk of lithogenesis. This metaphylactic effect needs to be confirmed in a well designed, prospective, randomized clinical study. Use of CAN during pregnancy was considered safe and well tolerated. However, given that there are some study limitations, as with most drugs, CAN should be administered during pregnancy with caution, especially during the first trimester, and only in approved indications. 


\section{Disclosure}

This review was supported by Bionorica SE, Neumarkt id Opf, Bayern, Germany.

\section{References}

1. Perepanova TS, Khazan PL. Phytopreparation Canephron ${ }^{\circledR} \mathrm{N}$ in the treatment and prophylaxis of urinary tract infections. Vrachebnoye Soslovie. 2005;5:44-46.

2. Sinyakova LA, Kosova IV. Prevention of urinary tract infection recurrences. Urologia. 2009;2:22-25.

3. Shaplygin LV, Monakov DM. Canephron ${ }^{\circledR} \mathrm{N}$ for treatment and prophylaxis of urolithiasis. Vrachebnoye Soslovie. 2004;7:22-24.

4. Repina MA, Kolchina VA, Kuzmina-Krutetskaya SR, Stambulova OA, Golubenko NA. Phytopreparations in the treatment of renal diseases in pregnant women and long-term safety results in born children. Journal of Obstetrics and Women's Diseases. 2006;1:50-56.

5. Ordzhonikidze NV, Yemelyanova AI, Petrova SB. Complication prevention and treatment in pregnants and puerperants with urinary tract diseases. Obstetrics and Gynaecology. 2009;6:41-45.

6. Voznesenskaya TS, Kutafina EK. Phytotherapy in the urinary system infection treatment in children. Pediatric Pharmacology. 2007;7:38-40.

7. Kirillov VI, Runenko VI, Bogdanova NA, Mstislavskaya SA. Complex therapy effects on the kidney function in children with vesicoureteral reflux in post-operative period. Questions of Contemporary Pediatrics. 2007;6:38-43.

8. Sukalo AV, Krokhina SA, Tur NI. Preparation Canephron ${ }^{\circledR} \mathrm{N}$ use in complex therapy of urinary system infections in children. Medical News. 2004;11:84-86.

9. Ivanov DD, Nazarenko VI, Kushnirenko SV, Krot VF, Taran EI. Phytotherapy of metabolic syndrome/type II diabetes: a potential for phytoneering. Health of the Ukraine. 2005;17:46-47.

10. Dudar IO, Loboda OM, Krot VF, Khimich VI, Kryzhanivska VM, Bryzhachenko TP. A 12-month comparative study of Canephron ${ }^{\circledR}$ $\mathrm{N}$ administration in the treatment of patients with the urinary tract infection. Zdorovie Muzhchiny. 2010;3:85-90.

11. Chernenko VV, Savchuk VI, Zheltovska NI, Shtilvaser LM. Peculiarities in correction of urinary $\mathrm{pH}$ and hypercristalluria in patients having uratolithiasis by means of phytopreparation Canephron ${ }^{\circledR}$ N. Zdorovie Muzhchiny. 2003;2:65-66.
12. Chernenko VV, Shtilvaser LM, Zheltovskaya NI. Contemporary approaches to pro- and metaphylactics of urolithiasis. Urologiya. 2005;4:2-4.

13. Medved VI, Islamova EV. To the question on safety of the preparation Canephron $^{\circledR} \mathrm{N}$ in the obstetric practice. Medical Aspects of Women's Health. 2009;4:32-35.

14. Medved VI, Bykova LM, Danylkiv OE, Shkabarovskaya EN. Pathogenetic justification and efficiency of improved therapy of pyelonephritis in pregnant women with diabetes mellitus. Women's Reproductive Health. 2003;2:35-38.

15. Potapo VA, Demchenko TV, Medvedev MV, et al. Pathogenetic therapy of gestational toxicosis in patients with renal disease. Health of the Ukraine. 2004;5:1-2.

16. Seymivskyy DA. Place of phyto-medication Canephron ${ }^{\circledR} \mathrm{N}$ in the treatment of urological diseases in children. Contemporary Pediatrics. 2010;2:178-181.

17. Ceban A. Efficacy of a fixed combination of Centaurii herba, Levistici radix and Rosmarini folium in urinary lithiasis. Results of an open randomised cohort study. Z Phytother. 2012;33:19-23.

18. Gaybullaev AA, Kariev SS. Effect of long-term Canephron ${ }^{\circledR} \mathrm{N}$ treatment on urinary risk factors associated with idiopathic calcium urolithiasis. Ärzte Zeitung online. [newspaper on the Internet]. Aug 2011. Available from: http://www.aerztezeitung.de/kongresse/mwi/mwi2011-urolith/. Accessed October 15, 2012. German.

19. Wilcox WR, KhalafA, Weinberger A, Kippen I, Klinenberg JR. Solubility of uric acid and monosodium urate. Med Biol Eng. 1972;10:522-531.

20. Pak CY, Water O, Arnold L, Holt K, Cox C, Barilla D. Mechanism for calcium urolithiasis among patients with hyperuricosuria: supersaturation of urine with respect to monosodium urate. J Clin Invest. 1977;59:426-431.

21. Türk C, Knoll T, Petrik A, Sarica K, Straub M, Seitz C. Guidelines on urolithiasis. Feb 2012. Available from: http://www.uroweb.org/gls/ pockets/english/22_Urolithiasis.pdf. Accessed October 15, 2012.

22. Grabe M, Bjerklund Johansen TE, et al. Guidelines on urological infections. Mar 2009. Available from: http://www.uroweb.org/gls/ pdf/17_Urological\%20infections_LR\%20II.pdf. Accessed October 15, 2012.
Research and Reports in Urology

\section{Publish your work in this journal}

Research and Reports in Urology is an international, peer-reviewed, open access journal publishing original research, reports, editorials, reviews and commentaries on all aspects of adult and pediatric urology in the clinic and laboratory including the following topics: Pathology, pathophysiology of urological disease; Investigation and treatment of

\section{Dovepress}

urological disease; Pharmacology of drugs used for the treatment of urological disease. The manuscript management system is completely online and includes a very quick and fair peer-review system, which is all easy to use. Visit http://www.dovepress.com/testimonials.php to read real quotes from published authors. 